\title{
APLICAÇÃO DO VALOR JUSTO NOS ATIVOS BIOLÓGICOS: UM ESTUDO NO ZOOLÓGICO DE VOLTA REDONDA
}

\author{
Nome: Arthur Batista Oiticica \\ Instituição: Universidade Federal Fluminense - UFF \\ E-mail: arthurbatista@id.uff.br \\ Nome: Michel Santana Moreira \\ Instituição: Universidade Federal Fluminense - UFF \\ E-mail: michelsm@id.uff.br \\ Nome: Mariana Pereira Bonfim \\ Instituição: Universidade Federal Fluminense - UFF \\ E-mail: marianabonfim@id.uff.br
}

\section{RESUMO}

O presente trabalho busca reproduzir, contabilmente, o valor justo dos ativos biológicos do Zoológico Municipal de Volta Redonda. Dada a crescente demanda por trabalhos com foco em gestão ambiental após a publicação do CPC 29, percebe-se a necessidade de avaliação fidedigna do valor dos animais pertencentes aos zoológicos visto que sua exposição é fonte de recursos indireta e a existência do comércio/permuta entre zoológicos. É possível aplicar o CPC 29 no tratamento contábil do Zoológico de Volta Redonda? Demonstra-se a conta de ativo biológico, calculada a valor justo, contendo 232 dos 275 animais em exibição, posição essa de 2016. Concluiu-se que, caso o zoológico dispusesse de um núcleo para efetuar o acompanhamento das variações patrimoniais, as mesmas estariam sendo representadas fidedignamente.

Palavras-chave: Ativos Biológicos. Valor Justo. Zoológico.

\begin{abstract}
This paper aims to reproduce, or account for, the fair value of the biological assets of the Volta Redonda Municipal Zoo. Given the growing demand for works focusing on environmental management after the publication of CPC 29 , it is necessary to have a reliable assessment of the value of animals belonging to zoos since their exposure is a source of indirect resources and trade / exchange permit between zoos. Is it possible to apply CPC 29 in the accounting treatment of the Volta Redonda Zoo? Demonstrate a biological asset account, calculated at fair value, containing 232 of the 275 animals on display, 2016 position.
\end{abstract}


Concluded that if the case or the zoo has a core for monitoring or following up the heritage actions, as they are being represented faithfully.

Keywords: Biological Assets. Fair Value. Zoo.

\section{INTRODUÇÃO}

A Ciência Contábil evolui para atender à necessidade humana de avaliação do patrimônio, seja ele de pessoas jurídicas como também de pessoas físicas. Dos primeiros registros da era da pedra aos elaborados controles atuais, a necessidade de mensurar o patrimônio traz a relevância do estudo da contabilidade.

O ramo socioambiental da contabilidade surge a partir da necessidade de avaliar os danos causados ao meio ambiente na cadeia produtiva. Em 1981, criou-se no Brasil a política nacional do meio ambiente através da Lei nº 6.938, de 31 de agosto de 1981 (BRASIL, 1981).

A preocupação com o tratamento dos ativos e passivos ambientais ampliou-se após debates internacionais na ONU e seu estudo em 1987, intitulado "Our common future" (IMPERATIVES, 2008), a agenda global por mudanças. No Brasil, em 1992, a conferência Eco-92 estabeleceu critérios para o trabalho dos gestores em todo o mundo com foco no meio ambiente e na atuação das corporações.

Em paralelo a esse cenário, a globalização das empresas exigia a parametrização dos relatórios contábeis que pudessem ser comparados e avaliados em diferentes países. A convergência das normas internacionais contábeis e o início da vigência da Lei no 11.638/07 movimentaram o Brasil para a aderência das normas do International Accounting Standards Board (IASB) que por sua vez publica orientações através das International Financial Reporting Standards - IFRS - e das International Accounting Standards - IAS (FERREIRA, 2003).

Para amenizar as discrepâncias quanto à contabilização de ativos biológicos e produtos agrícolas das empresas nacionais e internacionais e contribuir para a efetivação do plano de convergência aos padrões internacionais (CPC, 2008), o Comitê de Pronunciamentos Contábeis (CPC) aprovou, em agosto de 2009, o Pronunciamento Técnico CPC 29 - Ativos 
Biológicos e Produtos Agrícolas. Desse modo, o CPC 29 sendo a representação nacional do IAS 41- Agriculture, normatiza o tratamento contábil do grupo ativo biológico e produto agrícola no Brasil.

Tendo em vista que o estudo do grupo é complexo dada às transformações que sofre durante sua vida, nascimento, crescimento, reprodução e morte, Brito (2010) comenta que o custo histórico seria incapaz de avaliar fidedignamente seu valor. Assim, o valor justo se mostra ferramenta ideal para valoração do patrimônio biológico das entidades já que esse acompanha as variações e atualiza, periodicamente, o seu valor, considerando perdas e ganhos.

Desse modo, o desafio desse trabalho é aplicar o CPC 29 - Ativo Biológico e Produto Agrícola, no Zoológico Municipal de Volta Redonda no Estado do Rio de Janeiro, a fim de encontrar um montante que represente fidedignamente o grupo de ativos biológicos do patrimônio da instituição. Com isso, deseja-se que, ao final do trabalho, seja possível responder ao seguinte problema de pesquisa: O CPC 29, mais especificamente, a avaliação a valor justo, é aplicável aos zoológicos?

A temática se torna intrincada devido à ausência de mercado legalizado das espécies de animais estudados, mas com alto índice de comércio seja por trocas e vendas entre zoológicos ou por mercado ilegal, aliado à escassez de publicações científicas nacionais com essa abordagem que atenua o embasamento teórico.

Segundo o relatório da Rede Nacional de Combate ao Tráfico de Animais (RENCTAS, 2014), realizado em parceria com o Instituto Brasileiro do Meio Ambiente e dos Recursos Naturais Renováveis - Ibama, estima-se que no Brasil o tráfico de animais movimente um mercado de $\mathrm{R} \$ 2.500 .000 .000,00$ (dois bilhões e quinhentos milhões de reais) por ano e que cerca de quatro milhões de animais circulam ilegalmente pelo país. Assim, os zoológicos são os principais atuantes no mercado legalizado de animais exóticos e silvestres, embora não seja o único.

A existência de um mercado traz a reflexão de como os zoológicos mensuram e registram contabilmente seus animais. De mesmo modo, se os instrumentos disponibilizados pela contabilidade no Brasil são suficientes para auxiliar o gestor na tomada de decisão sobre a mensuração dos ativos quando se trata de animais exóticos e silvestres. 


\section{Contabilidade}

\section{REFERENCIAL TEÓRICO}

\subsection{Ativos Biológicos}

O principal produto dos zoológicos é a possibilidade de contemplar animais de variadas espécies, que somente poderiam ser visitados em seu habitat natural, disponibilizando esse tipo de exibição. Assim, a preservação e cuidado dos animais, física e gerencial, são cruciais para a existência dos zoológicos.

As transações de animais entre organizações ocorrem rotineiramente sendo uma parcela considerável dos produtos nacionais. Nessa prerrogativa, o CPC emitiu, em 2009, o Pronunciamento de número 29 - Ativo Biológico e Produto Agrícola correspondente a IAS 41 - Agriculture, colaborando com a convergência às normas internacionais, a fim de amparar as demandas de reconhecimento, mensuração e divulgação desse grupo contábil.

O Brasil possui considerável parcela no mercado internacional de carne animal do mundo, mas também detentor da maior floresta do mundo com vasta diversidade de espécies de animais: O Brasil é um país com grande quantidade de agronegócios e um dos maiores do mundo, passando a praticar um novo modelo contábil na atividade rural, e isso tem causado um grande impacto na sua economia por essas mudanças no processo contábil (MARION, 2012, p. 33).

Assim, a preocupação com o tratamento dos ativos biológicos convergiu na parametrização do CPC 29, a fim de atender a demanda desse nicho específico. Segundo o CPC 29 (2009, p.4), define-se como ativo biológico o "conjunto de animais ou plantas vivos", definição a qual se difere do produto agrícola que são os produtos não processados gerados a partir do ativo biológico, por exemplo, a lã proveniente do carneiro. Os ativos biológicos divergem dos demais ativos de uma empresa por apresentarem constantes mutações (nascimento, crescimento, procriação e morte) e por ser seres vivos, tornando sua observação, constante requisito para a mensuração.

Transformação biológica compreende o processo de crescimento, degeneração, produção e procriação que causam mudanças qualitativa e quantitativa no ativo biológico (CPC 29, 2009, item 5). Anteriormente mensurados pelo custo, os ativos biológicos, a partir 
do pronunciamento CPC 29, devem ser mensurados a valor justo menos as despesas de vendas, exceto para casos em que não for possível encontrar o valor justo, sendo permitido assim, a sua contabilização pelo valor de custo (CPC 29, 2009).

O CPC 29 fornece os critérios para análise, evidenciação, mensuração e divulgação dos ativos biológicos de forma que especifica as mudanças inerentes ocorridas nesse grupo. Desse modo, orienta ao reconhecimento do ativo biológico quando, e somente quando, seu valor contábil puder ser mensurado, seja provável que futuros benefícios econômicos fluam para a entidade e o valor justo ou o custo do ativo, puderem ser mensurados confiavelmente.

As perdas e ganhos referentes a transformação biológica do ativo devem ser contabilizadas no resultado do período. Também devem ser agrupados por maturidade ou condições físicas, como os novilhos e bois de corte, por exemplo.

Assim, as observações aos itens supracitados colaboram para essa análise, de forma que enquadra os animais presentes no zoológico, no CPC 29, definindo o valor justo como o critério ideal para a mensuração dos animais silvestres e exóticos, embora o conceito de mercado ativo não seja difundido ao tratar desse tipo de objeto.

\subsection{Valor Justo}

A Lei $\mathrm{n}^{\circ}$ 11.638/07 traz o conceito de valor justo no Brasil: no artigo 183 da referida legislação é conceituado o que é valor justo e sua aplicabilidade na mensuração de ativos e passivos (COELHO; LINS, 2010).

O valor justo é o método para valoração de objetos patrimoniais, que reflete as mutações do patrimônio no mercado, acompanhando perdas e ganhos, e ajustando o valor real do objeto. A métrica de valor justo também é capaz de acompanhar as flutuações do valor contábil, evidenciado nas publicações das instituições, sendo a métrica de mensuração que mais se aproxima da realidade, respeitando a representação fidedigna das informações estabelecida no CPC 00 - Estrutura Conceitual.

Segundo o CPC 46 (2012), "o valor justo é o preço que seria recebido pela venda do ativo ou pago pela transferência de um passivo em uma transação não forçada entre 
participantes do mercado na data de mensuração". Assim, acompanha as oscilações de mercado para estabelecer o valor do objeto.

Atendidos todos os requisitos de uma negociação, o valor justo pode ser empregado com confiabilidade. No entanto, segundo Castro, Morch e Marques (2008), os parâmetros brasileiros quanto ao valor justo não são claros, sendo por vezes confundidos com o valor de mercado. Tal fato exige maior atenção do pesquisador que deve observar as características do objeto estudado, a fim de respeitar as normas vigentes de contabilização.

A observação da norma, no intuito de minimizar a possibilidade de erros, se torna essencial visto que a tênue linha entre os conceitos de valor justo e valor de mercado podem ser confundidos. Para se obter o valor justo de um bem, a métrica considera o mercado ativo aquele no qual a empresa normalmente negocia. Caso, esse mercado não esteja disponível, orienta-se que siga para o mercado mais vantajoso, e atualizar a métrica sempre que as seguintes causas ocorrerem: “a) novos mercados surgirem; b) novas informações se tornarem disponíveis; c) informações utilizadas anteriormente não mais estiverem disponíveis; d) houver uma melhora nas técnicas de avaliação; ou e) houver mudanças nas condições de mercado" (CPC 46, 2012).

Outro importante conceito que o CPC 46 normatiza, é a hierarquia do valor justo, que pode ser dividida em nível 1, nível 2 e nível 3, dependendo dos critérios utilizados na mensuração que podem ser observados nos itens 76, 81 e 86 do CPC 46:

Nível 1 são observáveis no mercado, refletindo cotação de preços de ativos ou passivos idênticos em mercados ativos. Esta é a evidência mais confiável do fair value.

Nível 2 são observáveis no mercado - excetuando-se a cotação de ativos ou passivos - em mercados ativos onde a entidade tenha a possibilidade de acessar na data de mensuração. Neste grupo inclui-se a cotação de ativos ou passivos similares em mercados ativos, a cotação de ativos ou passivos idênticos em mercados não ativos, e informações de mercados que são diretamente observáveis para o ativo ou passivo, como por exemplo, taxas de juros e volatilidade.

Nível 3 não são observáveis no mercado, sendo - por exemplo - informações derivadas de extrapolações e interpolações que não podem ser corroboradas por informações observáveis do mercado (CPC 46, 2012). 
Assim, a norma ampara o gestor na mensuração do objeto quando não for possível verificar o preço praticado no mercado ativo. Castro, Morch e Marques (2008), comentam sobre os métodos de avaliação do fair value, que nada mais é do que o valor justo, que estão dentro dos níveis já citados pela norma, e os divide em valor de mercado, valor de cotação, valor de troca, valor de produtos similares e valor obtido por técnicas de valorização.

Dessa forma, é possível minimizar as discrepâncias na contabilização dos objetos patrimoniais dando amparo aos gestores na mensuração e divulgação dos objetos avaliados. Assim é preciso observar os parâmetros estabelecidos pelo CPC no intuito de uniformizar a informação produzida.

\section{METODOLOGIA}

O presente artigo se fundamentou em pesquisa bibliográfica, nos Pronunciamentos Técnicos 29 e 46 e em leis do sistema jurídico brasileiro. O trabalho elaborado por Freire et al. (2012) no Jardim Zoológico de Brasília foi utilizado como base para reprodução deste trabalho, sendo aplicado no Zoológico Municipal de Volta Redonda, escolhido mediante a sua grande importância para a região sul-fluminense.

Vinculado à Secretaria Municipal de Meio Ambiente da prefeitura de Volta Redonda, na cidade do Rio de Janeiro, o Zoológico Municipal situa-se em área de Mata Atlântica em torno da Floresta da Cicuta, sendo a última amostra intacta de Mata Atlântica no Vale do Paraíba do Sul (COSTA, 2004).

Teixeira, Irineu e Santos (2016) informam que o Zoológico de Volta Redonda é um zoológico ímpar, pois é o único na região sul-fluminense e único do interior do estado do Rio de Janeiro a não cobrar entrada de seus visitantes pedindo, atualmente, somente uma taxa colaborativa que não é obrigatória.

Segundo o site oficial, o zoológico recebe mensalmente cerca de 6.000 mil pessoas, entre moradores, estudantes, pesquisadores e turistas de toda região. Embora não seja possível mensurar o impacto monetário para a economia, sabe-se que o zoológico fomenta a circulação de dinheiro na cidade através dos mercados, postos de gasolina, fast food, etc. Além de atrair 
turistas, o Zoológico Municipal de Volta Redonda desenvolve atividades de recreação para habitantes, como visitas monitoradas, científica para os alunos que o usam como embrião de pesquisas, saúde veterinária e para animais debilitados que podem ser consultados no Hospital Veterinário Sebastião Sensaltas dos Santos.

Para a coleta dos dados foram feitas duas entrevistas nos dias 8 e 22 de novembro de 2017 com o responsável pelo Zoológico, onde foi apresentado o censo de animais disponíveis até dezembro de 2016. Mediante a falta de informação dos valores dos animais em exposição foi realizada, no dia 24 de março de 2018, outra entrevista, mas desta vez na Secretaria de Administração do Município de Volta Redonda onde não foram encontrados dados referentes as atuais espécimes. Mediante a inexistência de informações disponíveis sobre os seus valores contábeis, coletou-se em sítios, nacionais e internacionais, que promovem a comercialização legalizada dos variados animais.

\section{ANÁLISE DOS RESULTADOS}

O Zoológico Municipal de Volta Redonda adquire seus animais por meio de permuta, apreensão e transferência intermediadas pelo Ibama que detém o controle dos animais que estão em posse do zoológico através do censo anual.

O Zoológico, até o fim dessa pesquisa, não possuía controle contábil de seus ativos. Entretanto, deve-se levar em conta que o Zoológico Municipal faz parte do Ente Público Municipal e os seus ativos devem constar no Balanço Patrimonial do mesmo. O grupo de Ativo Permanente ou Ativo Não Financeiro deve ser composto pelos bens móveis e imóveis, semoventes e valores controlados pela entidade. O controle dos animais que estão no zoológico, realizado pelos responsáveis do mesmo e disponibilizados para a confecção dessa pesquisa, diz respeito a dados sobre a quantidade, espécie e ano de aquisição dos animais, sendo apresentada a posição final de 2016.

Assim, dos animais estudados, 27 espécies com total de 43 animais foram desconsideradas da avaliação visto que a aplicação de técnicas previstas no CPC 46 para obtenção do valor justo poderia gerar distorções no objeto estudado devido suas 
características taxonômicas inerentes a cada indivíduo que os definem únicos, dificultando a classificação como produtos similares, permitida pelo CPC 46. São essas as espécies: Araçari Poca, Babuíno Verde, Bem-te-vi, Bugio, Cachorro do Mato, Coruja Murucututu, Galo da Campina, Gavião Caboclo, Gavião Carcará, Gavião Carijó, Gavião Carrapateiro, Gavião do Rabo Branco, Gralha do Campo, Jaguatirica, Macaco Aranha da Cara Branca, Macaco Barrigudo, Macaco Rhesus, Mutum de Penacho, Onça Parda, Onça Pintada, Papagaio Moleiro, Pássaro Preto, Pomba de Coleira, Sabiá do Campo, Sanhaço Cinzento, Tucano de Peito Branco e Urubu Rei.

Foram analisados 232 animais que se dividem entre aves, mamíferos e répteis. Para evidenciação do valor justo foi aplicada a métrica de valor de mercado de acordo com o nível 1 que busca itens idênticos no mercado ativo. Assim, a síntese da análise pode ser observada na tabela 1:

Tabela 1: Contabilização dos Ativos Biológicos

\begin{tabular}{|l|c|cc|}
\hline \multicolumn{1}{|c|}{ Ativo Biológico } & Qtd & \multicolumn{2}{c|}{ Valor } \\
\hline Aves & 105 & $\mathrm{R} \$$ & $212.231,21$ \\
\hline Mamíferos & 41 & $\mathrm{R} \$$ & $496.816,02$ \\
\hline Répteis & 86 & $\mathrm{R} \$$ & $44.696,06$ \\
\hline Total & $\mathbf{2 3 2}$ & $\mathbf{R} \$$ & $\mathbf{7 5 3 . 7 4 3 , 2 9}$ \\
\hline
\end{tabular}

Fonte: Dados da Pesquisa.

A tabela elucida que, dos animais avaliados, o ativo biológico do zoológico possui valor de mercado significativo e alta liquidez, caso houvesse intenção de venda. Os criadores que possuem sites de venda exibem espécies, principalmente aves exóticas e silvestres, lembrando, por vezes, sites de bens de consumo.

No entanto, animais exóticos e silvestres se diferem dos animais criados para consumo por não possuírem mercado formal tangendo a complexidade da mensuração desses animais a valor justo já que a comercialização é regulada e em alguns casos específicos, proibida.

O zoológico recebe grande parte do seu acervo por doação, logo, a contabilização pelo custo menos as despesas e depreciação acumulada, conforme orienta o CPC 29 para ativos biológicos, não se aplica. 
Como a técnica de determinação de valor pelo mercado fornece grau de confiança maior de acordo com o CPC 46 (2012), no item 77 "o preço cotado em mercado ativo oferece a evidência mais confiável do valor justo", o quadro 1 evidencia os sites que forneceram o preço dos ativos biológicos constantes neste trabalho, a quantidade de cada animal, o valor total por espécie e as classes taxonômicas, possibilitando uma análise abrangente e segmentada dos dados.

Quadro 1: Valor de mercado dos animais do Zoológico de Volta Redonda

\begin{tabular}{|c|c|c|c|c|c|}
\hline Animal & Qtd & & Mercado & Total & Classe \\
\hline \multirow[b]{2}{*}{ Ananaí } & 2 & $\mathrm{R} \$$ & 80,00 & 160,00 & Ave \\
\hline & \multicolumn{5}{|c|}{$\begin{array}{l}\text { https://produto.mercadolivre.com.br/MLB-917063762-marrecos-lindo-casal-de- } \\
\text { marrecos-_JM }\end{array}$} \\
\hline \multirow{2}{*}{ Arara Canga } & 1 & $\mathrm{R} \$$ & $5.400,00$ & $5.400,00$ & Ave \\
\hline & \multicolumn{5}{|c|}{ http://criadouropassaredo.com.br/loja/reserva-pre-paga/9-arara-macao.html } \\
\hline \multirow{2}{*}{ Arara Canindé } & 7 & $\mathrm{R} \$$ & $3.300,00$ & $23.100,00$ & Ave \\
\hline & \multicolumn{5}{|c|}{ https://criatoriovaleverde.com.br/plus/modulos/conteudo/?tac=tabela-de-precos } \\
\hline \multirow{2}{*}{$\begin{array}{l}\text { Arara Vermelha } \\
\text { Grande }\end{array}$} & 3 & $\mathrm{R} \$$ & $5.000,00$ & $15.000,00$ & Ave \\
\hline & \multicolumn{5}{|c|}{ https://criatoriovaleverde.com.br/plus/modulos/conteudo/?tac=tabela-de-precos } \\
\hline \multirow{2}{*}{ Ararajuba } & 5 & $\mathrm{R} \$$ & $4.600,00$ & $23.000,00$ & Ave \\
\hline & \multicolumn{5}{|c|}{ https://criatoriovaleverde.com.br/plus/modulos/conteudo/?tac=tabela-de-precos } \\
\hline \multirow{2}{*}{ Avestruz } & 2 & $\mathrm{R} \$$ & $1.300,00$ & $2.600,00$ & Ave \\
\hline & \multicolumn{5}{|c|}{ http://www.vendadeavestruz.com.br/produtos_finalizados/pagina/2 } \\
\hline \multirow[b]{2}{*}{ Bigodinho } & 2 & $\mathrm{R} \$$ & 400,00 & 800,00 & Ave \\
\hline & \multicolumn{5}{|c|}{$\begin{array}{l}\text { http://animais-estimacao.com/aves-vende/Vende_Se_Bigodinho_Africano- } \\
\text { iid266412.htm }\end{array}$} \\
\hline \multirow{2}{*}{ Canário da Terra } & 4 & $\mathrm{R} \$$ & 400,00 & $1.600,00$ & Ave \\
\hline & \multicolumn{5}{|c|}{ http://www.ninhodoscolibris.com.br/index.php/vendas } \\
\hline \multirow{2}{*}{ Cardeal do Nordeste } & 1 & $\mathrm{R} \$$ & 704,25 & 704,25 & Ave \\
\hline & \multicolumn{5}{|c|}{ http://www.birdsexpress.net/red-capped-cardinal.html } \\
\hline
\end{tabular}




\begin{tabular}{|c|c|c|c|c|c|}
\hline \multirow{2}{*}{ Coleirinho } & 8 & $\mathrm{R} \$$ & 700,00 & $5.600,00$ & Ave \\
\hline & \multicolumn{5}{|c|}{ http://www.ninhodoscolibris.com.br/index.php/vendas } \\
\hline \multirow{2}{*}{ Corrupião } & 1 & $\mathrm{R} \$$ & $1.000,00$ & $1.000,00$ & Ave \\
\hline & \multicolumn{5}{|c|}{ http://www.mfrural.com.br/detalhe/casal-de-corrupiao-sofre--141761.aspx } \\
\hline \multirow{2}{*}{ Curió } & 1 & $\mathrm{R} \$$ & 400,00 & 400,00 & Ave \\
\hline & \multicolumn{5}{|c|}{ http://www.ninhodoscolibris.com.br/index.php/vendas } \\
\hline \multirow{2}{*}{ Ema } & 1 & $\mathrm{R} \$$ & $1.037,50$ & $1.037,50$ & Ave \\
\hline & \multicolumn{5}{|c|}{ https://www.saa.co.uk/189658.html } \\
\hline \multirow{2}{*}{ Emu } & 12 & $\mathrm{R} \$$ & $3.500,00$ & $42.000,00$ & Ave \\
\hline & \multicolumn{5}{|c|}{ http://www.criadourobelasaves.com.br/aves-disponiveis/internacionais/emu-adulto } \\
\hline \multirow{2}{*}{ Faisão Canário } & 3 & $\mathrm{R} \$$ & 250,00 & 750,00 & Ave \\
\hline & \multicolumn{5}{|c|}{ https://avesdecorativas.lojaintegrada.com.br/faisao-canario } \\
\hline \multirow{2}{*}{ Faisão de Coleira } & 1 & $\mathrm{R} \$$ & 60,00 & 60,00 & Ave \\
\hline & \multicolumn{5}{|c|}{ https://avesdecorativas.lojaintegrada.com.br/faisao-coleira } \\
\hline \multirow{2}{*}{ Ganso Australiano } & 1 & $\mathrm{R} \$$ & $1.500,00$ & $1.500,00$ & Ave \\
\hline & \multicolumn{5}{|c|}{ https://www.avesdecorativas.com.br/ganso-cereopsi } \\
\hline \multirow{2}{*}{ Gavião Quiri-quiri } & 1 & $\mathrm{R} \$$ & 900,00 & 900,00 & Ave \\
\hline & \multicolumn{5}{|c|}{ http://fukui5.wixsite.com/criadourofukuirj/blank } \\
\hline \multirow{2}{*}{ Irerê } & 1 & $\mathrm{R} \$$ & 229,46 & 229,46 & Ave \\
\hline & \multicolumn{5}{|c|}{ https://www.fincacasarejo.com/catalogo/detalle/dendrocygna-viduata } \\
\hline \multirow{2}{*}{ Jandaia } & 16 & $\mathrm{R} \$$ & 700,00 & $11.200,00$ & Ave \\
\hline & \multicolumn{5}{|c|}{ https://criatoriovaleverde.com.br/plus/modulos/conteudo/?tac=tabela-de-precos } \\
\hline \multirow{2}{*}{ Jandaia Sol } & 1 & $\mathrm{R} \$$ & $1.600,00$ & $1.600,00$ & Ave \\
\hline & \multicolumn{5}{|c|}{ https://criatoriovaleverde.com.br/plus/modulos/conteudo/?tac=tabela-de-precos } \\
\hline \multirow{2}{*}{ Maracanã Nobre } & 8 & $\mathrm{R} \$$ & $1.080,00$ & $8.640,00$ & Ave \\
\hline & \multicolumn{5}{|c|}{ http://criadouropassaredo.com.br/loja/reserva-pre-paga/17-ararinha- } \\
\hline
\end{tabular}




\begin{tabular}{|c|c|c|c|c|c|c|}
\hline & nobre.h & $\operatorname{arch}$ & papagaio\& & esults & & \\
\hline \multirow{2}{*}{$\begin{array}{l}\text { Maracanã } \\
\text { Verdadeira }\end{array}$} & 6 & $\mathrm{R} \$$ & $1.200,00$ & $\mathrm{R} \$$ & $7.200,00$ & Ave \\
\hline & \multicolumn{6}{|c|}{ http://www.criadouropedrabranca.com.br/comprar-passaro/ararinha-maracana/ } \\
\hline \multirow{2}{*}{$\begin{array}{l}\text { Papagaio do } \\
\text { Mangue }\end{array}$} & 4 & $\mathrm{R} \$$ & $2.250,00$ & $\mathrm{R} \$$ & $9.000,00$ & Ave \\
\hline & \multicolumn{6}{|c|}{$\begin{array}{l}\text { http://criadouropassaredo.com.br/loja/reserva-pre-paga/3-papagaio-do- } \\
\text { mangue.html?search_query=papagaio\&results }=6\end{array}$} \\
\hline \multirow{2}{*}{$\begin{array}{l}\text { Papagaio } \\
\text { Verdadeiro }\end{array}$} & 2 & $\mathrm{R} \$$ & $3.150,00$ & $\mathrm{R} \$$ & $6.300,00$ & Ave \\
\hline & \multicolumn{6}{|c|}{ http://criadouropassaredo.com.br/loja/reserva-pre-paga/2-papagaio-verdadeiro.html } \\
\hline \multirow[b]{2}{*}{ Pavão } & 2 & $\mathrm{R} \$$ & 650,00 & $\mathrm{R} \$$ & $1.300,00$ & Ave \\
\hline & \multicolumn{6}{|c|}{$\begin{array}{l}\text { http://fazendavisconde.com.br/tabela.asp?subcategoria=Pav\%F5es\&categoria=Aves } \% 20 \\
\text { Ornamentais }\end{array}$} \\
\hline \multirow[b]{2}{*}{ Periquito Rei } & 1 & $\mathrm{R} \$$ & 350,00 & $\mathrm{R} \$$ & 350,00 & Ave \\
\hline & \multicolumn{6}{|c|}{$\begin{array}{l}\text { http://criadouropassaredo.com.br/loja/reserva-pre-paga/12-periquito- } \\
\text { rei.html?search_query=rei\&results=1 }\end{array}$} \\
\hline \multirow{2}{*}{ Suindara } & 1 & $\mathrm{R} \$$ & 800,00 & $\mathrm{R} \$$ & 800,00 & Ave \\
\hline & \multicolumn{6}{|c|}{ http://onde-comprar-preco-de.animais-estimacao.com/?encontrar=coruja+suindara } \\
\hline \multirow{2}{*}{$\begin{array}{l}\text { Tucano de Bico } \\
\text { Preto }\end{array}$} & 2 & $\mathrm{R} \$$ & $5.000,00$ & $\mathrm{R} \$$ & $10.000,00$ & Ave \\
\hline & \multicolumn{6}{|c|}{$\begin{array}{l}\text { http://www.anypets.com.br/tucano-bico-preto-ramphastos-vitellinus-consulte- } \\
\text { disponibilidade-p51 }\end{array}$} \\
\hline \multirow{2}{*}{ Tucano Toco } & 3 & $\mathrm{R} \$$ & $6.000,00$ & $\mathrm{R} \$$ & $18.000,00$ & Ave \\
\hline & \multicolumn{6}{|c|}{ http://mundoexoticopet.com.br/aves/tucano/tucano-toco } \\
\hline \multirow{2}{*}{ Tucanuçu } & 2 & $\mathrm{R} \$$ & $6.000,00$ & $\mathrm{R} \$$ & $12.000,00$ & Ave \\
\hline & \multicolumn{6}{|c|}{ http://mundoexoticopet.com.br/aves/tucano/tucano-toco } \\
\hline \multirow{2}{*}{ Anta } & 2 & $\mathrm{R} \$$ & $3.820,00$ & $\mathrm{R} \$$ & $87.640,00$ & Mamífero \\
\hline & \multicolumn{6}{|c|}{ http://www.exoticanimalsforsale.net/sale/6956-zoo-born-Brazilian-Tapirs.asp } \\
\hline \multirow[b]{2}{*}{ Babuíno Sagrado } & 1 & $\mathrm{R} \$$ & $2.500,00$ & $\mathrm{R} \$$ & $2.500,00$ & Mamífero \\
\hline & \multicolumn{6}{|c|}{$\begin{array}{l}\text { Artigo: "Valor justo dos ativos biológicos: um estudo sobre a aplicabilidade do CPC } 29 \\
\text { em um jardim zoológico" (Freire, et al. 2012) }\end{array}$} \\
\hline Cervo Samba & 19 & $\mathrm{R} \$$ & $3.300,00$ & $\mathrm{R} \$$ & $62.700,00$ & Mamífero \\
\hline
\end{tabular}




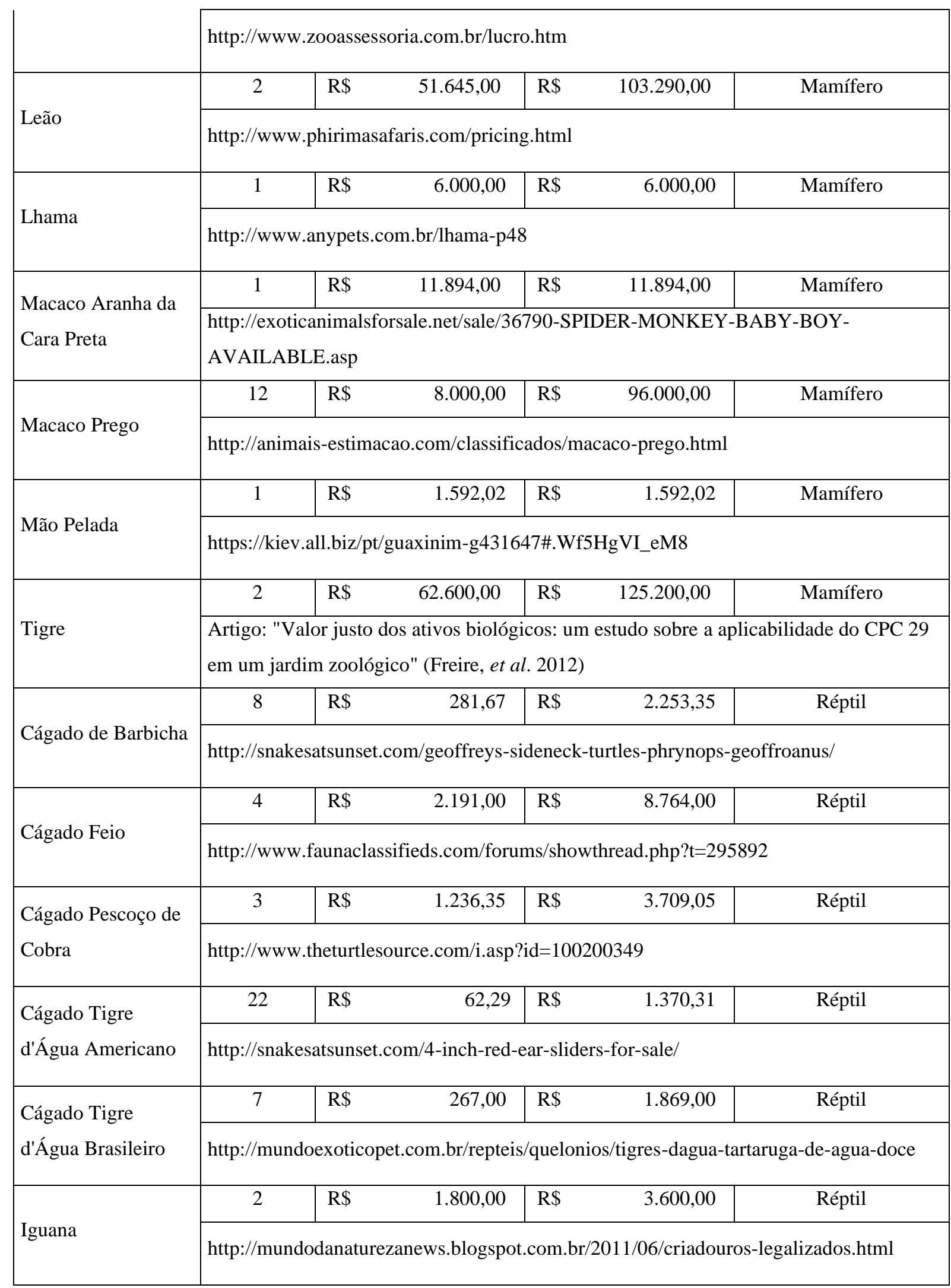




\begin{tabular}{|c|c|c|c|c|c|c|}
\hline \multirow{2}{*}{ Jabuti Piranga } & 31 & $\mathrm{R} \$$ & 490,00 & $\mathrm{R} \$$ & $15.190,00$ & Réptil \\
\hline & \multicolumn{6}{|c|}{ http://www.reservaromanetto.com.br/comocomprarjabutis.php } \\
\hline \multirow{2}{*}{ Jabuti Tinga } & 5 & $\mathrm{R} \$$ & 250,00 & $\mathrm{R} \$$ & $1.250,00$ & Réptil \\
\hline & \multicolumn{6}{|c|}{ http://revistabichos.com.br/comprar-tartaruga-jabuti-conheca-mais-sobre-esse-bichinho/ } \\
\hline \multirow{2}{*}{$\begin{array}{l}\text { Jacaré do Papo } \\
\text { Amarelo }\end{array}$} & 1 & $\mathrm{R} \$$ & $3.000,00$ & $\mathrm{R} \$$ & $3.000,00$ & Réptil \\
\hline & \multicolumn{6}{|c|}{ https://www.pesca.agricultura.sp.gov.br/41_3_687-695.pdf } \\
\hline \multirow{2}{*}{ Jacaré Tinga } & 2 & $\mathrm{R} \$$ & $1.540,00$ & $\mathrm{R} \$$ & $3.080,00$ & Réptil \\
\hline & \multicolumn{6}{|c|}{ http://www.enimalia.com/crocodiles-for-sale } \\
\hline \multirow[b]{2}{*}{ Tracajá } & 1 & $\mathrm{R} \$$ & 610,35 & $\mathrm{R} \$$ & 610,35 & Réptil \\
\hline & \multicolumn{6}{|c|}{ http://www.theturtlesource.com/i.asp?id=100200410\&p=Yellow-Spotted-River-Turtle } \\
\hline TOTAL & 232 & $\mathbf{R} \$$ & $52.620,89$ & $\mathbf{R} \$$ & $753.743,29$ & \\
\hline
\end{tabular}

Fonte: Dados da Pesquisa.

Caso o zoológico dispusesse de um núcleo para efetuar o acompanhamento das variações patrimoniais do zoológico no quesito ativo biológico, mais especificamente, valor de cada animal, ele poderia representar, fidedignamente, a posição e as transações patrimoniais desses animais em seus demonstrativos contábeis.

\section{CONSIDERAÇÕES FINAIS}

Os ativos biológicos são objetos de tratamento contábil complexo devido suas características de mutação. Sua contabilização é, em alguns casos, desafio para o profissional que atua no ramo devido à falta de referências a serem seguidas e a normatização CPC 29 ser relativamente recente.

As empresas que destinam o ativo biológico para comercialização os evidenciam no grupo de estoque devido sua expectativa de rentabilidade gerada com a venda do ativo. No entanto, os zoológicos não estão diretamente alinhados com as empresas, visto que a 
inexistência de mercado regulado dificulta a evidenciação a valor justo dos animais exóticos e silvestres.

A contabilização dos ativos biológicos dos zoológicos não segue os mesmos princípios das empresas, no qual os seus animais possuem fácil acesso ao valor de mercado e recursos para estabelecer valores fidedignos. Diferentemente, os zoológicos detêm critérios específicos e nem sempre exatos para a evidenciação dos ativos mensurados principalmente quando os animais que são recebidos por transferência.

A falta de pessoal e de investimentos colabora para a desatenção no que tange ao controle contábil no Zoológico Municipal de Volta Redonda, uma vez que não há legislação que obrigue tal ação. Assim, os controles adotados atendem apenas às normas ambientais exigidas pelo Ibama no critério ambiental.

A partir da análise dos dados disponíveis se observa que o tratamento contábil dos animais não remete aos critérios estabelecidos no CPC 29 uma vez que os itens não são destinados à comercialização e que a expectativa de rentabilidade é intangível de modo que se espera lazer e bem-estar. Portanto, a legislação contábil vigente não oferece embasamento para esse público específico com relação aos ativos biológicos quando se trata de animais silvestres e exóticos.

A falta de mercado formal regulamentado para os animais exóticos e silvestres é uma das limitações da pesquisa. Outra limitação é a falta de controle contábil/patrimonial dos animais do Zoológico Municipal de Volta Redonda que impossibilita a verificação do impacto da avaliação a valor justo.

Portanto, para pesquisas futuras, recomenda-se aplicar os níveis 1, 2 e 3 do valor justo para acompanhamento das modificações dos ativos biológicos da instituição. Examinar de forma macro a estrutura do zoológico delineando o conceito de heritage asset considerando os custos para sustentação de sua estrutura e comparar com a composição patrimonial de outros zoológicos nacionais e internacionais. 


\section{REFERÊNCIAS}

BRASIL. Lei n. ${ }^{\circ} 6.938$ de 31 de agosto de 1981. Dispõe sobre a Política Nacional do Meio Ambiente, seus fins e mecanismos de formulação e aplicação, e dá outras providências. Disponível em: http://www.planalto.gov.br/ccivil_03/Leis/L6938.htm . Acesso em: 27 jul. 2018.

BRITO, E. de. Um estudo sobre a subjetividade na mensuração do valor justo na atividade pecuária bovina. 2010. 109f. Dissertação (Mestrado em Controladoria e Contabilidade) Departamento de Economia, Administração e Contabilidade de Ribeirão Preto, Universidade de São Paulo, Ribeirão Preto, 2010.

CASTRO, V. C. B.; MORCH, R. B.; MARQUES, J. A. V. C. Fair value accounting: uma análise sobre a evolução do conceito de valor justo entre as normas internacionais e as normas brasileiras. Sociedade, Contabilidade e Gestão, Rio de Janeiro, v. 3, nº 1, jan/jun 2008.

COELHO, C. U.; LINS, L. Teoria da Contabilidade. São Paulo: Editora Atlas, 2010.

COSTA, A. Volta Redonda ontem e hoje. Volta Redonda: Edição comemorativa 50 anos. Editor Jader Costa, 2004.

CPC - COMITÊ DE PRONUNCIAMENTOS CONTÁBEIS. A Busca da Convergência da Contabilidade aos Padrões Internacionais. 2008. Disponível em: http://cpc.org.br/pdf/CPCplano\%20de\%20converg\%C3\%AAncia\%20_\%20novembro\%20de\%202008_proposta.pdf. Acesso em: 27 jul. 2018.

CPC - COMITÊ DE PRONUNCIAMENTOS CONTÁBEIS. Pronunciamento Técnico CPC 29 - Ativo Biológico e Produto Agrícola. 2009. Disponível em: http://static.cpc.aatb.com.br/Documentos/324_CPC_29_rev\%2008.pdf. Acesso em: 27 jul. 2018. 
CPC - COMITÊ DE PRONUNCIAMENTOS CONTÁBEIS. Pronunciamento Técnico CPC 46 - Mensuração do Valor Justo. 2012. Disponível em: http://static.cpc.aatb.com.br/Documentos/395_CPC_46_rev\%2006.pdf. Acesso em: 27 jul. 2018

FERREIRA, A. C. de S. Contabilidade Ambiental: Uma Informação para o Desenvolvimento Sustentável. São Paulo: Atlas, 2003.

FREIRE, F. S. F.; PRADO, S. S.; MARQUES, M. M.; PEREIRA, E. M. Valor justo dos ativos biológicos: um estudo sobre a aplicabilidade do CPC 29 em um jardim zoológico. Gestão Contemporânea, Ano 9, n. 12, p. 207-233, Dez. 2012.

IMPERATIVES, S. Report of the World Commission on Environment and Development: Our Common Future. 2008. Disponível em: http://www.un-documents.net/our-commonfuture.pdf. Acesso em: 27 jul. 2018.

MARION, J. C. Contabilidade Rural, 13ª ed. São Paulo: Atlas, 2012.

RENCTAS - REDE NACIONAL DE COMBATE AO TRÁFICO DE ANIMAIS. $1^{\circ}$ Relatório Nacional sobre o Tráfico de Fauna Silvestre. 2014. Disponível em: http://www.renctas.org.br/wp-content/uploads/2014/02/REL_RENCTAS_pt_final.pdf.

Acesso em: 26 nov. 2018.

TEIXEIRA, J. B.; IRINEU, L. E. S. S.; SANTOS, N. T. Análise Quantitativa de Visitas Monitoradas do Zoológico Municipal de Volta Redonda em 2015. In: Congresso Nacional de Meio Ambiente de Poços de Caldas, 13, 2016, Poços de Caldas/MG. Anais... Minas Gerais: Congresso Nacional de Meio Ambiente de Poços de Caldas, 2016. 